\title{
Study of Jatropha Curcas Extract as a Corrosion Inhibitor in Acidic Medium on Mild Steel by Weight Loss and Potentiodynamic Methods
}

\author{
Dipak Kumar Gupta ${ }^{1,2}$, KM Anita Kafle ${ }^{1}$ Anju Kumari Das ${ }^{2}$, Shova Neupane ${ }^{3}$, Anita Ghimire ${ }^{2}$, \\ Braham Dev Yadav ${ }^{4}$, Yogesh Chaudhari², Nabin Karki², Amar Prasad Yadav² \\ ${ }^{1}$ Tri-Chandra Multiple Campus, Tribhuvan University, Kathmandu, Nepal \\ ${ }^{2}$ Central Department of Chemistry, Tribhuvan University, Kirtipur, Kathmandu, Nepal \\ ${ }^{3}$ Centre National de la Recherche Scientifique (CNRS), Paris, France \\ ${ }^{4}$ R.R.M. Campus, Tribhuvan University, Janakpur, Nepal \\ *CorrespondingE-mail: amar2y@yahoo.com
}

(Received: March 31, 2020; Revised: June 2, 2020 \& Accepted: June 24, 2020)

\begin{abstract}
The corrosion inhibition properties of methanol extract of Jatropha curcas (JC) were investigated for mild steel (MS) in acidic medium using weight loss and potentiodynamic methods. Corrosion inhibition of MS in $1 \mathrm{M} \mathrm{H}_{2} \mathrm{SO}_{4}$ was studied in the absence and presence of various concentrations of the methanolic extract of Jatropha curcas barks. The results showed an increase in corrosion inhibition with increasing concentration of the extract. The inhibition efficiency of $1000 \mathrm{ppm}$ JC extract from the weight loss and potentiodynamic polarization methods were approximately $92.0 \%$ after 24 hours immersion in the acidic solution. Open circuit potential (OCP) and potentiodynamic polarization measurements showed that the JC extract acts as a mixedtype inhibitor.
\end{abstract}

Keywords: Corrosion inhibition, green inhibitor, potentiodynamic polarization, mild steel, weight loss

\section{Introduction}

In the last few decades, with industrialization, corrosion control has remained an issue. It has estimated that approximately $3-4.5 \%$ of the Gross National Products (GNP) of an industrialized nation lost due to corrosion [1]. Therefore, corrosion control has become a global concern. Several methods, like organic, inorganic, and polymers coatings, are applied to prevent corrosion. However, in recent years, there is a growing trend to use green inhibitors because of its non-hazardous, cheap, readily availability, ecofriendly, and biodegradability [2,3]. Plants are a source of such green inhibitors. Extracts of plant leaves, barks, fruits, seeds, and roots have been reported as a corrosion inhibitor in the acidic medium [4-7]. The extraction of natural products from plants is a cheap and straight forward method. The use of plant extracts as green corrosion inhibitors for metals such as iron $[8,9]$, mild steel $[4-6,10]$, aluminum $[7,11,12]$, copper
[13] are reported. The inhibition effect of plant extract is due to the presence of alkaloids, flavonoids, and tannins compounds [2,14]. These phytochemicals contain nitrogen, oxygen, sulfur, and phosphorous, which helps forming a protective film on the metal surface by physisorption or chemisorption, reducing corrosion $[15,16]$.

Nepal is rich with widespread biodiversity. The various types of flora and fauna flourish in the Himalayan to the Terai region. It inspires the use of natural products as a corrosion inhibitor, which is ecofriendly and greener. Lantana camara [17], Euphorbia royleana [18], Artemesia vulgaris [19], Pogostemon benghalensis [20], Calotropis gigantean [21] have been studied as a green corrosion inhibitor, and they have shown inhibition efficiency above 90\%. The leaves, stem, and oil of Jatropha curcas have shown productive corrosion inhibition efficiency against mild steel (MS) in the acidic medium [22-24]. 
Rukaiyat et al. [25] studied the corrosion inhibition of alkaloids and tannins extract of jatropha stem bark onto mild steel. The inhibition efficiency of alkaloids rich extract of Jatropha curcas is reported to be superior to tannins extract.

Jatropha curcas is a multipurpose, drought-resistant, perennial plant capable of loping on marginal land unsuitable for dryland agriculture. It contains phenols, alkaloids, glycosides, flavanoids, saponins, free amino acids, and phytic acid. However, its constituents and quantity vary depending upon the altitude and parts of plants [26]. Nepal government has developed a national program since 2007 for the promotion of this plant as feedstock for biodiesel and established an Alternative Energy Promotion Center (AEPC) to implement the plans for alternative energies [27]. Thus, this study aims to examine corrosion inhibition properties of high altitude Jatropha curcas barks of Nepalese origin by weight-loss and potentiodynamic polarization methods. A methanolic extract of bark at different concentrations has been tested as a corrosion inhibitor on MS in acidic medium.

\section{Materials and Methods}

\section{Preparation of mild steel sample}

Mild steel (MS) sheet purchased from the local vendor of Kathmandu Valley was mechanically cut into samples of a dimension of $3 \mathrm{~cm} \times 3 \mathrm{~cm} \times 0.1$ $\mathrm{cm}$. MS samples were polished with Silicon carbide (SiC) paper of \#100 to \#2000 grits. Abraded samples were ultrasonicated in ethanol, dried, and stored in desiccators. These samples were used for weight loss measurements and potentiodynamic polarization.

\section{Preparation of plant extract}

The fresh barks of Jatropha curcas were collected from Haramtari, Gorkha, Nepal (Lng:84.6272661, Lat:27.9924422, Elevation: 1016m) and washed, cut, shade dried and powdered. The extract was prepared by cold percolation in methanol using $50 \mathrm{~g}$ of powder in $400 \mathrm{~mL}$ of methanol and allowed to stand for four days so that compounds of powder get dissolved in the solvent. The mixture was filtered, followed by evaporation to get the extract. This process was repeated, and the extract was evaporated in a water bath to obtain a dry solid extract of JC.

\section{Preparation of inhibitor solution}

$1 \mathrm{~g}$ extract was dissolved in $1000 \mathrm{~mL}$ of $1 \mathrm{M} \mathrm{H}_{2} \mathrm{SO}_{4}$ by using a magnetic stirrer. The resulting solution was filtered to remove undissolved extract, and it was taken as a 1000 ppm inhibitor stock solution in acid. From the stock solution, solutions of $800,600,400$, and $200 \mathrm{ppm}$ were prepared using serial dilution in 1 $\mathrm{M} \mathrm{H}_{2} \mathrm{SO}_{4}$ solution.

\section{Corrosion test by weight loss method}

The weight loss was determined from the difference of sample weighed before and after immersion in acid and inhibitor solutions. The effect of immersion time and inhibitor concentration in the corrosion rate was studied by weight loss. The MS samples were immersed in $1 \mathrm{M} \mathrm{H}_{2} \mathrm{SO}_{4}$ and $1000 \mathrm{ppm}$ inhibitor solutions for different time intervals $(3,6,9,12$, and $24 \mathrm{~h}$ ) to study the effect of immersion time. Similarly, the effect of inhibitor concentrations was studied by immersing samples in acid and various concentrations of inhibitor solutions $(200,400,600,800$, and 1000 $\mathrm{ppm}$ ) for 6 hours. The following relations determined the corrosion rate $(\mathrm{CR})$, surface coverage $(\theta)$, and inhibition efficiency (IE\%):

Corrosion Rate $(\mathrm{CR})=\frac{\text { Weight loss }(\mathrm{W})}{\operatorname{Area}(\mathrm{A}) \mathrm{x} \text { time }(\mathrm{t}) \mathrm{x} \operatorname{density}(\mathrm{d})} \times 8.76 \times 10^{4}$

Where, $W$ is weight loss of the MS ( $\mathrm{g}$ ) after immersion time, $t$ (hours), A is the area of the MS $\left(\mathrm{cm}^{2}\right)$, and $\mathrm{d}$ is

$$
\text { Surface Coverage }(\theta)=\frac{W_{o}-W i}{W_{o}}
$$

Inhibition Efficiency $(I E) \%=\frac{W_{0}-\mathrm{Wi}}{\mathrm{W}_{0}} \times 100$

the density of the MS $\left(\mathrm{g} \mathrm{cm}^{-3}\right)$.

Where, $\mathrm{W}_{\mathrm{o}}$ is the weight loss of the MS in the absence of inhibitor, and $\mathrm{W}_{\mathrm{i}}$ is the weight loss of the MS in the presence of inhibitor.

\section{Corrosion test by potentiodynamic polarization}

Electrochemical measurements were carried out using a three-electrode system consisting of the MS sample as a working electrode, a saturated calomel electrode 
(SCE) as a reference, and a graphite rod as a counter electrode. All the potential values hereafter are referred to as SCE. A Hokuto Denko potentiostat (HA151) was used to make potentiodynamic polarization. Open circuit potential (OCP) was measured for 30 minutes at an interval of 2 minutes before each potentiodynamic polarization of the MS in acid and various concentrations of inhibitor solutions to attain a steady-state condition. Then, the MS sample was subjected to potentiodynamic polarization from -1.6 $\mathrm{V}$ to $0.8 \mathrm{~V}$ vs. SCE. From the polarization curves, the corrosion current $\left(I_{\text {corr }}\right)$, and corrosion potential $\left(E_{\text {corr }}\right)$ were determined from the Tafel extrapolation method,

$$
I E \%=\frac{\text { Icorr(uninhibited })- \text { Icorr(inhibited })}{\text { Icorr(Uninhibited })} \times 100
$$

and the following relation calculated corrosion Inhibition Efficiency (IE).

\section{Results and Discussion}

\section{Alkaloids test}

\begin{tabular}{c|c|c}
\hline Meyer's Test & Wagner's Test & Dragondroft's Test \\
+ & + & + \\
\hline
\end{tabular}

The phytochemical screening of the methanolic extract of Jatropha curcas (JC) revealed the presence of alkaloids using three standard test methods.

\section{Effect of immersion time}

Corrosion rate, surface coverage, and inhibition Table 1: Corrosion rate, surface coverage, and inhibition efficiency of the JC extract at different immersion time.

\begin{tabular}{|c|c|c|c|c|}
\hline \multirow{2}{*}{$\begin{array}{l}\text { Time } \\
\text { (hours) }\end{array}$} & \multicolumn{2}{|l|}{ Corrosion rate (mm/year) } & \multicolumn{1}{c|}{$\begin{array}{c}\text { Surface } \\
\text { coverage ( } \boldsymbol{\theta})\end{array}$} & $\begin{array}{l}\text { Inhibition } \\
\text { efficiency\% }\end{array}$ \\
\cline { 2 - 3 } & For acid & $\begin{array}{l}\text { For inhibitor } \\
\text { solution }\end{array}$ & & \\
\hline 3 & 112.93 & 17.64 & 0.843 & 84.37 \\
\hline 6 & 115.64 & 15.22 & 0.868 & 86.83 \\
\hline 9 & 108.42 & 14.58 & 0.865 & 86.55 \\
\hline 12 & 110.07 & 11.72 & 0.893 & 89.35 \\
\hline 24 & 102.85 & 8.17 & 0.92 & 92.05 \\
\hline
\end{tabular}

efficiency of JC extract obtained from weight loss measurements for different time intervals are given in table 1.

Figure 1 shows the variation of corrosion rate with immersion time with and without inhibitor. The results show a significant effect of the JC extract on the corrosion rate of MS in acid solution. The extract has decreased the MS sample's corrosion rate by about 6 to 12 times during its immersion period.

The decrease of the corrosion rate is attributed to the adsorption of phytochemicals present in the extract. The inhibition efficiency of $1000 \mathrm{ppm}$ concentration of plant extract for a period of $3,6,9,12$, and $24 \mathrm{~h}$ is shown in Figure 2.

The inhibition efficiency of JC extract after 24 hours

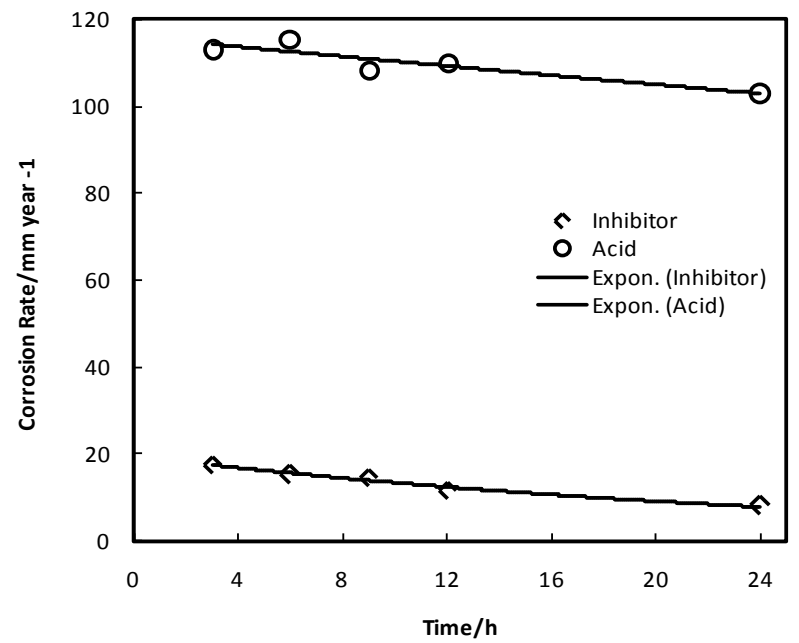

Figure 1: Variation of corrosion rate with immersion time of the MS in presence and absence of $1000 \mathrm{ppm}$ inhibitor solution in $1 \mathrm{M} \mathrm{H}_{2} \mathrm{SO}_{4}$ solutions

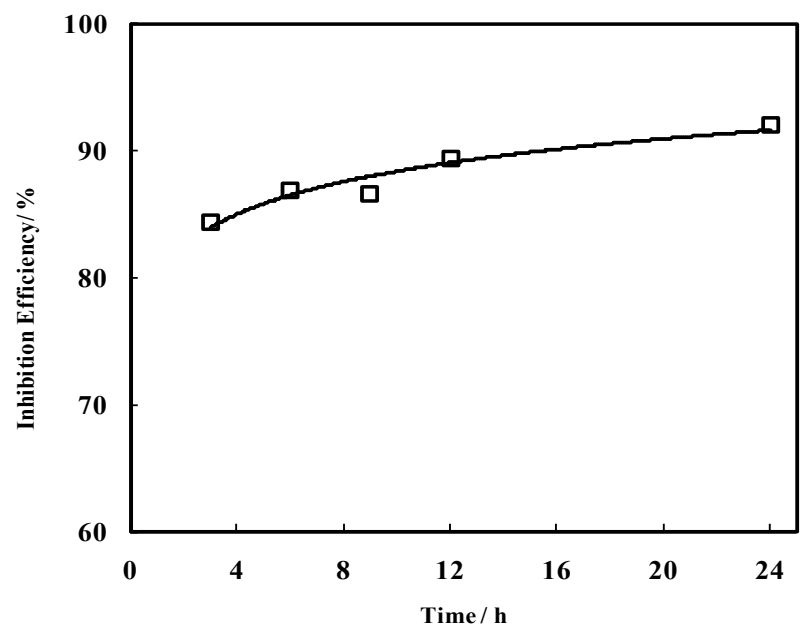

Figure 2: Variation of inhibition efficiency of JC extract with immersion time in 1000 ppm inhibitor solution in $1 \mathrm{M} \mathrm{H}_{2} \mathrm{SO}_{4}$ solutions

of immersion is found to be approximately $92.00 \%$. It shows the surface coverage of the MS by the extract increases with the time of immersion.

\section{Effect of concentration}


Corrosion rate, surface coverage, and inhibition efficiency of various JC extract concentrations for 6 hours immersion are given in table 2. Table 2 clearly shows that the corrosion rate decreased with the increase in the concentration of extract. Figure 3 shows that the inhibition efficiency increases with an increase in the concentration of the JC extracts. Similar observations have been reported for JC leaf extract when the gravimetric method was used [22,25]. The results suggest that an increase in ex tract concentration increases the number of inhibitor molecules available for the adsorption onto the MS surface. It results in decreasing the surface area available for the direct acid attack on the metal surface [28]. The inhibition efficiency of $1000 \mathrm{ppm}$ concentration of JC extract after $6 \mathrm{~h}$ immersion is approximately $82.85 \%$.

\section{Open circuit potential (OCP)}

Table 2: Corrosion rate, surface coverage and inhibition efficiency of the extract of JC at different concentrations

\begin{tabular}{c|c|c|c|c}
\hline $\begin{array}{l}\text { Conc. } \\
\text { (ppm) }\end{array}$ & $\begin{array}{l}\text { Weight } \\
\text { loss(g) }\end{array}$ & $\begin{array}{l}\text { Corrosion rate } \\
\text { (mm/year) }\end{array}$ & $\begin{array}{l}\text { Surface } \\
\text { coverage( } \boldsymbol{\theta})\end{array}$ & $\begin{array}{l}\text { Inhibition } \\
\text { efficiency \% }\end{array}$ \\
\hline Acid & 1.10873 & & & \\
200 & 0.6322 & 63.13 & 0.4297 & 42.97 \\
400 & 0.5603 & 55.89 & 0.4946 & 49.46 \\
600 & 0.4766 & 48 & 0.5701 & 57.01 \\
800 & 0.2906 & 29.08 & 0.7389 & 73.89 \\
1000 & 0.1901 & 17.78 & 0.8285 & 82.85 \\
\hline
\end{tabular}

Figure 4 shows the effects of inhibitor concentrations on the OCP change of the immersed MS sample in JC extract solution for 24 hours. The OCP shifts to the anodic direction compared to the acid solution. The general trend is that the time required to reach a stable OCP value depends on the concentration of the extract.

A higher concentration attains a steady-state OCP value faster compared to a lower concentration of the extract. The shift of OCP to positive direction with the addition of JC extract hints to the adsorption of inhibitor molecules on the MS surface, forming a barrier for the aggressive acid solution [28]. The OCP for $1000 \mathrm{ppm}$ of JC extract is $-0.444 \mathrm{~V}$ after $24 \mathrm{~h}$ of immersion. However, the shift in OCP value compared to the acid only solution is less than $30 \mathrm{mV}$, which confirms that the extract of JC acts as a mixed type inhibitor.

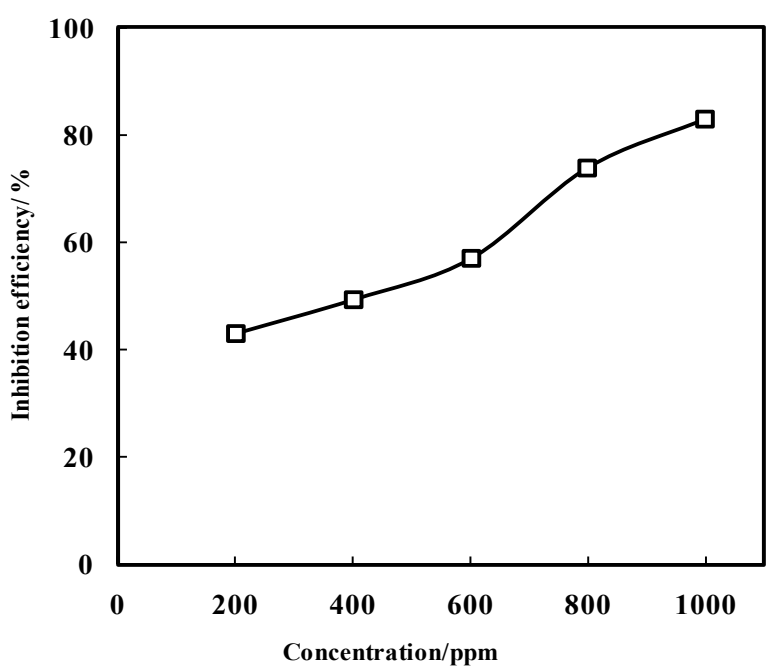

Figure 3: Variation of inhibition efficiency with different concentrations of JC extract in $1 \mathrm{M} \mathrm{H}_{2} \mathrm{SO}_{4}$ for 6 hours open to air by weight loss method

\section{Potentiodynamic polarization of mild Steel (MS)}

The potentiodynamic polarization was performed in the presence and absence of the acidic inhibitor solutions. The polarization behavior of MS sample was recorded for the different concentrations (200, $400,600,800$, and $1000 \mathrm{ppm}$ ) of plant extract in $1 \mathrm{M}$ $\mathrm{H}_{2} \mathrm{SO}_{4}$ solution after $24 \mathrm{~h}$ immersion and after $30 \mathrm{~min}$ immersion (as immersed) to understand the effect of immersion time on the inhibition efficiency of the JC extract. For simplicity, only results for 200, 600, and 1000 ppm inhibitor concentrations are plotted. Figures 5 and 6 show the effect of the inhibitor's concentration on the MS sample's polarization behavior for

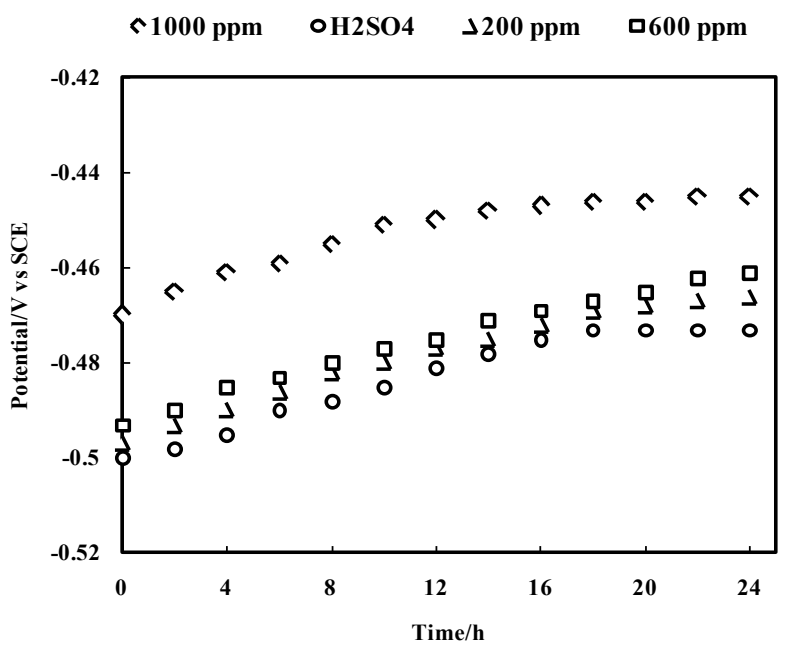

Figure 4: Variation of OCP with time of immersion of the $\mathrm{MS}$ sample in $1 \mathrm{M} \mathrm{H}_{2} \mathrm{SO}_{4}$ and $1 \mathrm{M} \mathrm{H}_{2} \mathrm{SO}_{4}$ containing various concentrations of extract of JC 
as immersed and after $24 \mathrm{~h}$ immersion samples, respectively. The figure reveals only a marginal shift of OCP, confirming a mixed type behavior of the inhibitor molecules. However, a significant decrease in the current of the cathodic curve is obtained upon the addition of the extract, which shows the inhibitive behavior of the extract of JC. Nevertheless, the cathodic curves maintain a parallel line, and therefore the mechanism of corrosion is not affected. The inhibitor molecules form a barrier layer by adsorbing on the MS surface and suppress the hydrogen reduction reaction. Therefore, the dissolution of the iron decreased.

Figure 6, obtained after $24 \mathrm{himmersion}$ in acidic solutions containing different JC extract concentrations, reveals that current density decreased more significantly with an increase in the concentration of inhibitor. The suppression of corrosion with elongation of immersion time shows that sufficient time should be allowed for better adsorption of the inhibitor molecules [24]. It is seen that the cathodic and anodic branches of the polarization curves are affected by the adsorption of the phytochemicals of JC extracts. However, both the polarization curves show parallel behavior, and therefore mechanisms of corrosion are not influenced by the inhibitor molecules. Both metallic dissolution and hydrogen evolution reactions are consequently retarded by the adsorbed phytochemical on the metal surfaces [28]. The inhibition action of 1000 ppm of JC extract is found to be highly effective in both cases. Therefore, the results confirm that the

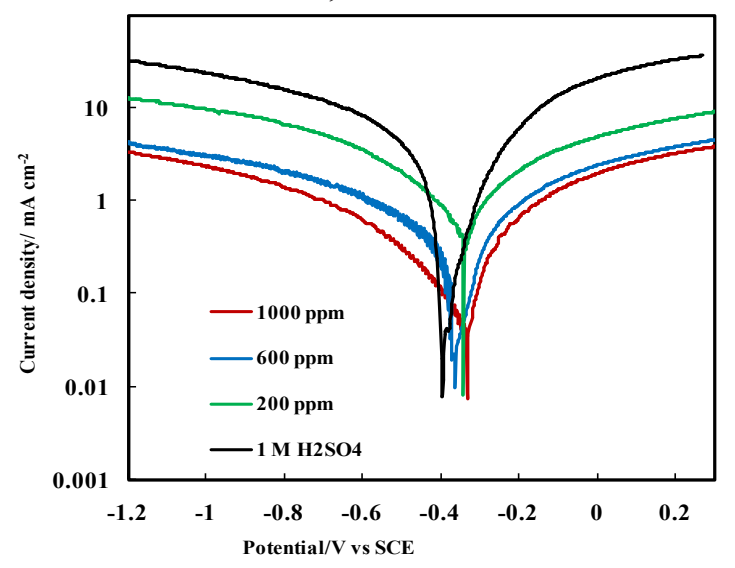

Figure 5: Effects of concentration of JC extract solution on the polarization behavior of the $\mathrm{MS}$ in $1 \mathrm{M} \mathrm{H}_{2} \mathrm{SO}_{4}$ after 30 min immersed (as immersed)

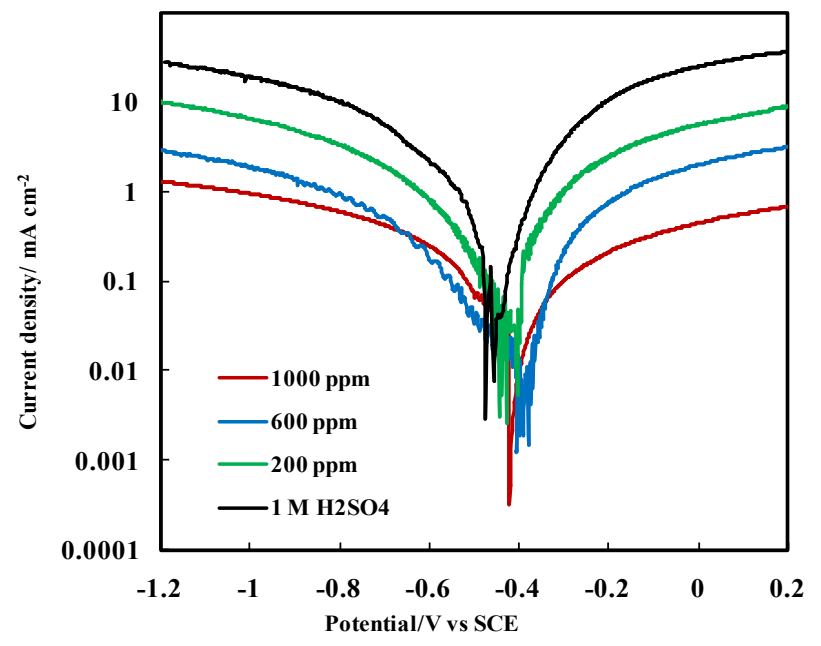

Figure 6: Effects of concentration of JC extract solution on the polarization behavior of the $\mathrm{MS}$ in $1 \mathrm{M} \mathrm{H}_{2} \mathrm{SO}_{4}$ after for $24 \mathrm{~h}$ immersion.

extract of bark of Jatropha curcas acts as an effective corrosion inhibitor for corrosion protection of MS in acidic medium.

\section{Effect of concentration on inhibition efficiency}

The effect of different JC bark extract concentrations on its inhibition efficiency was studied to explore the influence of inhibitor concentration on the inhibition efficiency of the extract. The inhibition efficiency was determined from the potentiodynamic polarization of Figure 5, and Figure 6. Figure 7 represents the plot of inhibition efficiency against the various concentration of extract, which reveals that the inhibition efficiency of the JC extract on the MS increased with increasing

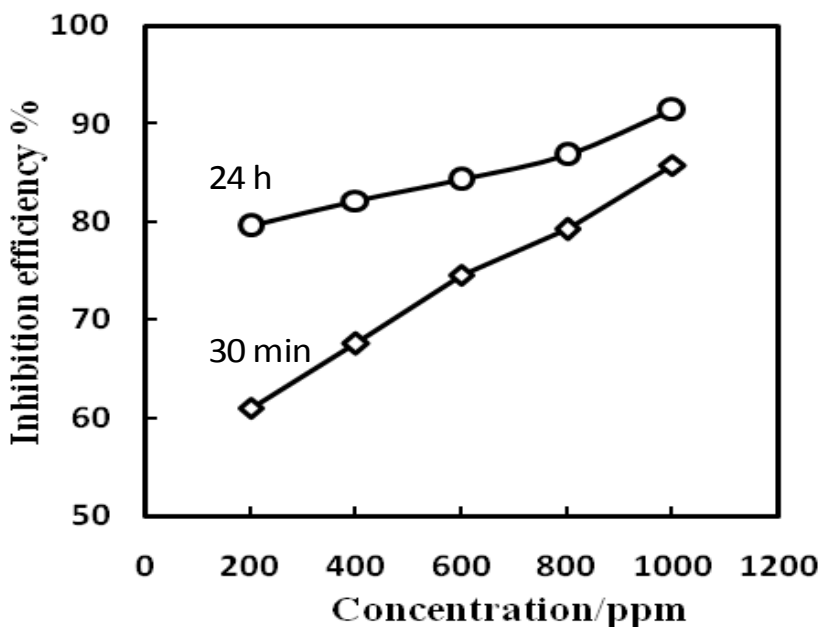

Figure 7: Effect of immersion time and concentration of inhibitor solutions on the inhibition efficiency of JC extract on corrosion of $M S$ in acidic medium 
concentration of the JC extract.

This is because the fraction of the surface covered by the adsorbed molecules increased with an increase in concentration. The maximum inhibition efficiency (IE) is $85.75 \%$ and $91.34 \%$ for $1000 \mathrm{ppm}$ concentration of extract when the sample is immersed for $30 \mathrm{~min}$. After $24 \mathrm{~h}$ immersion in an acidic solution containing JC extract, respectively.

The inhibition efficiency increased progressively as the concentration of the extract increased in the case of short immersion time (30 $\mathrm{min})$, but a marginal increase in inhibition efficiency is seen in the MS sample immersed for a long time (24 h). In addition, even after 30 min immersion, the inhibition efficiency significantly increased and this shows the importance of concentration. It reflects that an optimized condition should be used for practical application of inhibitor so that the MS surface gets completely covered by inhibitor molecules. This is also supported by the result obtained from the weight loss method.

\section{Conclusion}

The study shows that Jatropha curcas bark is an excellent eco-friendly corrosion inhibitor of mild steel (MS) in $1 \mathrm{M} \mathrm{H}_{2} \mathrm{SO}_{4}$. The addition of bark extract drastically reduced the weight loss of the mild steel sample due to the adsorption of phytochemical constituents of the methanolic extract of bark. The concentration influences inhibition efficiency on the inhibitor and immersion time. The inhibition efficiency of $1000 \mathrm{ppm} \mathrm{JC}$ extract from the weight loss method is found to be $82.85 \%$ at $25{ }^{\circ} \mathrm{C}$ for 6 hours immersion in acidic solution and $92.05 \%$ for 24 hours immersion in the same solution. Potentiodynamic polarization and OCP measurement show that the $J C$ extract act as a mixed type inhibitor for corrosion of mild steel in acidic solution. The inhibitor molecules suppress both cathodic and anodic reactions by barrier effect. The reaction mechanism is not affected by the JC extract.

\section{Acknowledgments}

The authors would like to thank Central Department of Chemistry, Tribhuvan University and Tri- Chandra Multiple Campus, Ghantaghar, and Kathmandu to provide laboratory facilities to carry out this work.

\section{References}

1. Z. Ahmad, Principle of Corrosion Engineering and Corrosion Control, $1^{\text {st }}$ Ed., ButterworthHeinemann, 2006, 223-250.
2. A. Y. El-Etre, M. Abdallah and Z. E. El-Tantany, Corrosion inhibition of some metals using Lawsonia extract, Corrosion Science, 2005, 47 (2), 385-395.

3. J. Buchweishaija and G. S. Mhinzi, Natural products as a source of environmentally friendly corrosion inhibitors: the case of gum exudates from Acacia seyal var. seyal, Portugaliae Electrochimica Acta, 2008, 26(3), 257-265.

4. A. M. Abdel-Gaber, B. A. Abd-El-Nabey, I. M. Sidahamed, A. M. Ei-Zayady and M. Saadawy, Inhibitive action of some plant extracts on the corrosion of steel in acidic media, Corrosion science, 2006, 48, 2765-2779.

5. E. E. Oguzie, Studies on the inhibitive effect of Ocimum virdis extract on the acid corrosion of mild steel, Materials Chemistry and Physics, 2006, 99, 441-446.

6. P. C. Okafor, I. E. Uwah, O. O. Ekerenam and U. J. Ekpe, Combretum bracteosum extracts as eco-friendly corrosion inhibitor for mild steel in acidic medium, Pigment \& Resin Technology, 2009, 38(4), 236-241

7. E. E. Oguzie, A. I. Onuchukwu, P. C. Okafor and E. E. Ebenso, Corrosion inhibition and adsorption behavior of Ocimum basilicum extract on aluminium, Pigment \& Resin Technology, 2006, 35(2), 63-70.

8. D. Kesavan, M. Gopiraman, N. Sulochana, Green inhibitors for corrosion of metals: a review, Chemical Science Review and Letters, 2012, 1(1), 1-8.

9. A. Chetouani, B. Hammouti and M. Benkaddour, Corrosion inhibition of iron in hydrochloric acid solution by jojoba oil, Pigment \& Resin Technology, 2004, 33(1), 26-31.

10. F. Zucchi and I. H. Omar, Plant extracts as corrosion inhibitors of mild steel in $\mathrm{HCl}$ solutions, Surface Technology, 1985, 24(4), 391-399.

11. I. B. Obot, N. O. Obi-Egbedi and S. A. Omoren, Antifungal drugs as corrosion inhibition for aluminium in $0.1 \mathrm{M} \mathrm{HCl}$, Corrosion Science, 2009, 51(8), 1868-1875

12. R. A. Ukpe, S. A. Odoemelam, A. O. Odiongenyi and N. Eddy, Inhibition of the corrosion of 
aluminium in $0.1 \mathrm{M} \mathrm{HCl}$ by ethanol extract of mango peel waste (EMPW), December 5, 2014.

13. O. K. Abiola, M. O. John, P. O. Asekunowo, P. C. Okafor and O. O. James, 3[(4-amino-2-methyl5-pyrimidinyl)]-5-(2-hydroxyethyl)-4-methyl thiazolium chloride hydrochloride as green corrosion inhibitor of copper in $\mathrm{HNO}_{3}$ solution and its adsorption characterstic, Green Chemistry Letters and Reviews, 2011, 3, 273-279.

14. S. Martinez, Inhibitory mechanism of mimosa tannin using molecular modeling and substitutional adsorption isotherms, Materials Chemistry and Physics, 2003, 77(1), 97-102.

15. E. E. Oguzie and E. E. Ebenso, Studies on the corrosion inhibiting effect of congo red dye halide mixtures, Pigment \& Resin Technology, 2006, 35 (1), 30-35.

16. S. J.Zakvi and G. N. Mehta,Acid corrosion ofmild steel and its inhibition by Swertia anngustifoliastudy by electrochemical techniques, Transaction of The SAEST,1988, 23(4), 407-410.

17. P. R. Shrestha, H. B. Oli, B. Thapa, Y. Chaudhary, D. K. Gupta, A. K. Das, K. B. Nakarmi, S. Singh, N. Karki and A. P. Yadav, Bark extract of Lantana camara in $1 \mathrm{M} \mathrm{HCl}$ as green corrosion inhibitor for mild steel, Engineering Journal, 2019, 23(4), 205-211. (DOI:10.4186/ej.2019.23.4.205).

18. B. Thapa, D. K. Gupta, A. P. Yadav, Corrosion inhibition of bark extract of Euphorbia royleana on mild steel in $1 \mathrm{M} \mathrm{HCl}$, Journal of Nepal Chemical Society, 2019, 40, 25-29. (DOI:10.3126/ jncs.v40i0.27274).

19. N. Karki, Y. Choudhary and A. P. Yadav, Thermodynamic adsorption and corrosion inhibition studies of mild steel by Artemisia vulgaris extract from methanol as green corrosion inhibitor in acid medium, Journal of Nepal Chemical Society, 2018, 39, 76-85. (DOI: 10.3126/ jncs.v39i0.27041).

20. Y. Choudhary, N. Karki and A. P. Yadav, Study of the corrosion inhibition behavior of Pogostemon benghalensis (Rudilo) for mild steel in acidic medium by weight loss method, Journal of Nepal Chemical Society, 2016, 35, 139-144.

21. P. S. Desai, Inhibitory action of extract of ankado (Calotropis gigantea) leaves on mild steel corrosion in hydrochloric acid solution, International Journal of Current Microbiology Applied Science, 2015, 4(1), 437-447.

22. O. M. Ajayi, J. K. Odusote, and R. A. Yahya, Inhibition of mild steel corrosion using Jatropha curcas leaf extract, Journal of Electrochemical Science and Engineering, 2014, 4(2), 67-74. (DOI: 10.5599/jese.2014.0046).

23. O. Olamide, O. F. Adekunle, A. A. Adesoji and O. A. Sunday, Corrosion inhibition of mild steel in seawater using Jatropha stem, Analele Universităţii “Eftimie Murgu” Reşiţa Anul XXIII, 2016, 1, 1453-7397.

24. O. Mokhtari, I. Hamdani, A. Chetouani, A. Lahrach, H. El Halouani, A. Aouniti and M. Berrabah, Inhibition of steel corrosion in $1 \mathrm{M} \mathrm{HCl}$ by Jatropha Curcas oil, Journal of Materials and Environmental Science, 2014, 5 (1), 310-319.

25. M. Said Rukaiyat, G. Salisu Abubakar and M. Kntapo Fatima, Corrosion inhibition of mild steel using alkaloids and tannins extracts of Jatropha Curcas in acidic media, Baeyor Journal of Pure and Applied Sciences, 2017, 10(1), 311-317. http://dx.doi.org/10.4314/bajopas.v10i1.62S

26. N. S. Tomar, M. Sharma, and R. M. Agarwal, Phytochemical analysis of Jatropha curcas L. during different seasons and developmental stages and seedling growth of wheat (Triticum aestivum L) as affected by extracts/leachates of Jatropha curcas L, Physiology and Molecular Biology of Plants, 2015, 21(1),83-92. https:// dx.doi.org/10.1007\%2Fs12298-014-0272-0.

27. A. Shrestha, A. Bhusal, P. Kayastha and S. Lamichhane, A case study on Jatropha curcas for biodiesel production in Nepal, submitted to Powershift Nepal Research and Policy Theme,2014.http://tude.org.np/wp-content/ uploads/2016/08/A-Case-Study-on-Jatrophacurcas.pdf, accessed on 24 March 2020.

28. N. Moussaoui, D. Zerouali and N. Bettahar, Inhibitive effect of date extract on the corrosion of carbon steel in acidic media, Journal of Chilean Chemical Society, 2016, 61(3), 3018-3024. 